\title{
Jujube, an Alternative Fruit Crop for the Southwestern United States
}

\author{
Shengrui Yao' \\ Department of Plant and Environmental Sciences, Sustainable Agriculture Science \\ Center at Alcalde, New Mexico State University, Alcalde, NM 87511 \\ Additional index words. Ziziphus jujuba, cultivar, flowering, fruiting, nutrition, propagation, processing
}

\begin{abstract}
Jujube (Ziziphus jujuba Mill.), also called chinese date, originated in China and has been cultivated there for over 4000 years (Guo and Shan, 2010; Liu and Wang, 2009; Qu and Wang, 1993). Jujube was derived from its wild relative - sour jujube (Ziziphus spinosa). During ancient times in China, people selected plants with large, good tasting fruit from sour jujubes and brought them home to plant $(\mathrm{Qu}$, 1963). Later, most jujube cultivars were selected through seedling selection or possible mutations (Guo and Shan, 2010; Liu and Wang, 2009). Now, there are over 800 jujube cultivars in China (Guo and Shan, 2010; Liu and Wang, 2009). In the United States, there are about 70 80 cultivars/selections. Jujube also has a relative indian jujube (Ziziphus mauritiana), a tropical plant, which will not be included in this paper.
\end{abstract}

\section{HISTORY IN THE UNITED STATES}

The early importations of jujubes into the United States were jujube seedlings with varying fruit quality (Rehder and Rixford, 1929; Yao, 2013). Starting in 1908, USDA Agricultural Explorer Frank N. Meyer imported jujube cultivars into the United States. From 1908 to 1918, Mr. Meyer imported 34 cultivars plus seeds of both jujubes and sour jujubes (Yao, 2013). Unfortunately, most of his importations were lost and only 'Li', 'Lang', 'Mu' (Mu Shing Hong Tsao), 'Shuimen', 'So', and 'Yu' are still available (Yao, 2013). Besides Frank Meyer's cultivar importation, there were other sources of jujube entering the United States (Yao, 2013). In the 19th and early 20th centuries, Chinese railroad and mine workers brought jujubes

\footnotetext{
Received for publication 15 Dec. 2015. Accepted for publication $20 \mathrm{Jan} .2016$.

This paper was part of the colloquium "Alternative Specialty Crop: Opportunities and Challenges," presented at the 2015 ASHS Conference, New Orleans, LA, on 4 Aug. 2015, and sponsored by the Working Group of Asian Horticulture, Tropical Horticulture Working Group, and Pomology Working Group

We thank Steve Guldan and Robert Heyduck from NMSU for reviewing this paper before submission. This paper is partially supported by the USDA Specialty Crop Block Grant through the New Mexico Department of Agriculture. This is also a contribution of the New Mexico Agricultural Experiment Station, New Mexico State University, Las Cruces, NM.

${ }^{1}$ Corresponding author. E-mail: yaos@nmsu.edu.
}

into the United States because they consumed jujubes as part of their diet. Along the railroads in the southwest, there are jujube plants which originated from discarded jujube seeds littered from the Chinese railroad and mine workers (J. Iglesias, personal communication). From El Paso, TX, Las Cruces and Silver City, NM, to Arizona, there are scattered jujube trees that bear fruit regularly. Jujubes have been planted at the University of Idaho Parma Research and Extension Center for nearly 20 years and 'Li' and 'Lang' perform well (E. Fallahi, personal communication). After Frank Meyer's importation, the USDA set up jujube trials in different states during the 1920 s to 1930 s. After those trials were ended, the remaining trees and other jujube trees in the United States were spread slowly through friends and families. Most of them had no names or were named causally after the town or family where they were located (Yao, 2013). With human selection, most of those surviving solitary trees were self-fruitful.

There were two old jujube trees at the old LC Ranch headquarters at Gila, NM. Those trees were planted by Thomas Lyons, the owner of LC Ranch at around 1900, but their original source was unknown (G. Van Auken, personal communication). After 115 years, these two trees still look healthy and set some fruit in 2015 (Fig. 1A and B). There were scattered trees with varied ages in backyards near Gila, Cliff, and Silver City, NM, and most of them were suckers from these two trees, and they were all heavily laden with uniform small fruit in 2015 (Fig. 1C and D). From Tornillo and Fabens to El Paso, TX, all the way to Las Cruces, NM, scattered bigfruited jujube trees of varied ages are not rare and some sour jujube plants are also found in these areas (Fig. 1E and F). Other states could have similar scattered jujube plantings (Lyrene, 1979), and all of those are potential germplasm for future cultivar selection or research purposes. More work is needed to explore and use this germplasm.

\section{JUJUBE FLOWERING AND FRUITING HABITS}

Jujube belongs to the Rhamnaceae family and its flower cluster is a cyme with 2 to 13 flowers (Liu, 2006; Yao, 2012). In China, jujubes have day blooming type and night blooming type (Qu et al., 1989). In the United States, they are morning type and afternoon type (Lyrene, 1983; Yao et al., 2015a). The morning type had sepal splitting from early morning to $1000 \mathrm{HR}$, whereas the afternoon type split between 1200 to 1600 HR. The morning blooming type in the United States is equivalent to the night blooming type, whereas the afternoon type is equivalent to the day type in China (Yao et al., 2015a). The 6-h shift in blooming time could be due to location and climate conditions (Lyrene, 1983; Yao et al., 2015a). Among the 56 cultivars/selections observed in New Mexico, 24 were morning type and 32 were afternoon type (Table 1) (Yao et al., 2015a). Heavy clouds/rainy weather delayed bloom but cultivars belonging to the same type still bloomed at a similar time. Jujube blooming habits are stable from year to year (Yao et al., 2015a).

Unlike pome fruit and stone fruit, jujube trees have flower bud initiation, bloom, fruit set, and maturation within one growing season. As a result, production is less affected by the previous year's weather and pest conditions (Guo and Shan, 2010; Yao, 2013), and this allows the tree to produce a reliable crop each year (Fairchild, 1918; Locke, 1948; Lyrene, 1979; Yao, 2012). Jujubes initiate their flowers as new shoots or branchlets appear. Shoot growth, flower bud initiation, blooming, fruit set, and fruit growth all happen simultaneously and compete for nutrients. With high nutrient competition, the jujube fruit set rate is low compared with other fruit species (Guo and Shan, 2010; Yao, 2013).

Jujube fruit commonly have one kernel (pit) in the middle except cultivar Pitless, which has an incomplete kernel inside. Some incomplete kernels are also found in some fruit of cultivars Lang, Li, and Redland. A hard kernel does not mean that seeds have formed inside. Cultivars Lang, Don Polenski, Junzao, and Thornless all have pear shaped fruit but form only a sac inside the pit. For breeding purposes or for medicinal effect of the seeds, scientists/consumers should be selective with cultivars. Table 2 lists the seed conditions of some jujube cultivars (Yao et al., 2015a).

\section{CULTIVARS IN THE UNITED STATES}

After jujube cultivars were imported into the USDA Plant Importation Station at Chico, CA, in 1908, scientists observed and researched the trees until the 1950s (Ackerman, 1961; Fairchild, 1918; Meyer, 1911, 1916). Among the four recommended cultivars in 1926 (Thomas, 1927), 'Li', 'Lang', and 


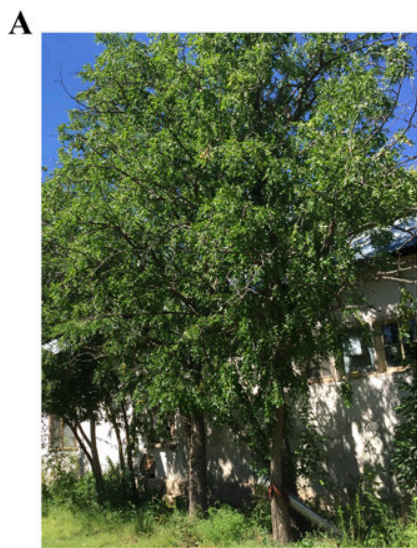

B

C

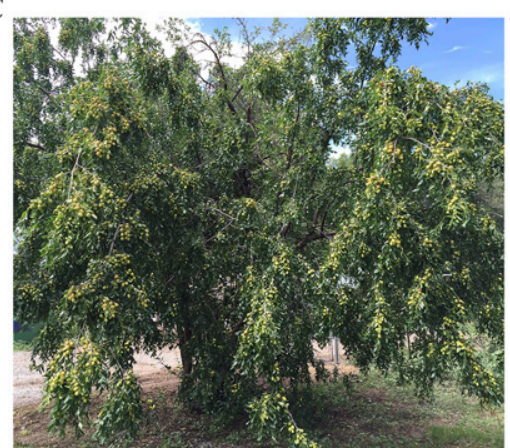

$\mathbf{E}$

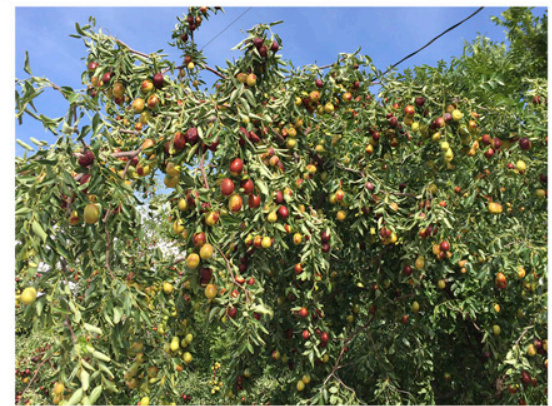

D
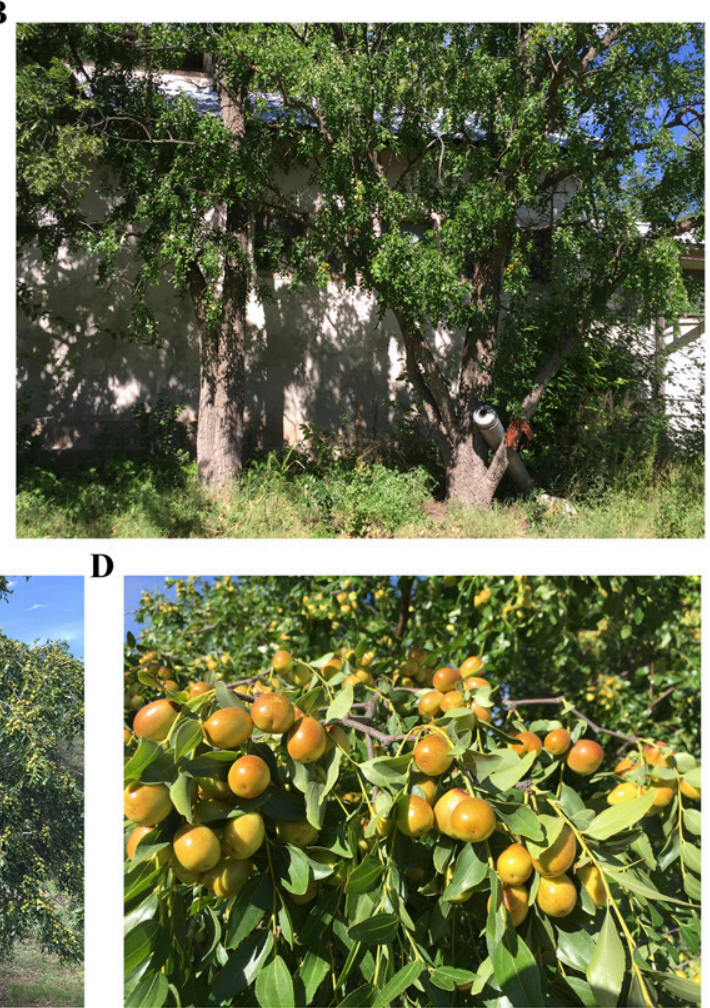

F

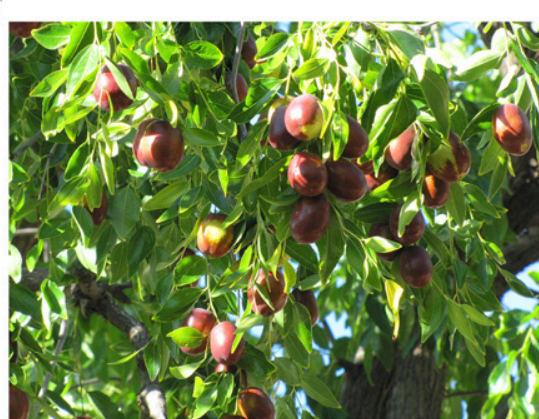

Fig. 1. Two old jujube trees at the old LC Ranch Headquarters in Gila, NM, in 2015 (A and B), tree transplanted from a suckers from one of those two trees at Silver City, NM, and its fruit in 2015 (C and D), and some big fruited jujube trees near Tornillo, TX, and Las Cruces, NM (E and F).

'Shuimen' were cultivars worth keeping based on our evaluation, but we have not harvested enough fruit for ' $\mathrm{Mu}$ ' to evaluate it. Fruit of 'Shuimen' is medium in size, pointed at the end, relatively loose in texture, and good for both fresh eating and drying. A special note for 'Shuimen' is its relatively low vitamin C content compared with other jujube cultivars (Yao, 2014).

In China, after thousands of years of cultivation, most cultivars were localized to one or a few provinces. During the species domestication and cultivar selection process, cultivars in the same region were more related to each other than those from regions farther away. Jujube cultivars in China were classified into 39 cultivar groups based on random amplified polymorphic DNA, amplified fragment length polymorphism, sequence-related amplified polymorphism fingerprints, and morphological characters (Li et al., 2009; Liu and Wang, 2009; Peng et al., 2000). In the United States, 100 years after importation, jujube has spread widely across the United States (Ashton, 2008; Brubaker, 1977; Locke, 1948; Lyrene and Crocker, 1994; Yao, 2013), but cultivar evaluation is very limited. Without formal cultivar descriptions, homonyms and synonyms could exist. In our jujube flowering and fruiting study, it was noticed that fresh eating cultivars $\mathrm{Li}, \mathrm{Li}-2$, and Redland were all self-fruitful with big fruit and loose texture, whereas 'Lang', 'Don Polenski', 'Ed Hegard', 'Thornless', and 'Junzao' (Lang group) were not self-fertile, with pear-shaped fruit containing no seed but a brown empty sac inside. The 'Lang' group could be closely related to each other or synonymous. 'Lang' in the United States is not the same as 'Lang' (郎零) in China as the two have different fruit shape. The U.S. 'Lang' looks similar to what are currently known as 'Junzao' (骏柊) or 'Hupingzao' (壶瓶寿) in China (Liu and Wang, 2009). More morphological, physiological, and molecular studies are needed to classify the jujube cultivars in the United States.

Over 50 cultivars are currently being evaluated at Alcalde, NM (Yao et al., 2015a) and cultivar trials are being initiated at different locations in New Mexico. A multistate cultivar trial is urgently needed to determine the adaptability of different cultivars to different regions and to recommend cultivars for different end uses in those regions.

\section{JUJUBE HARVESTING AND PROCESSING}

With easily bruised skin, jujube fruit for fresh eating should be handpicked, but for fruit for drying and processing, mechanical harvest is more practical and economical for commercial production. Pecan, walnut, and prune can be harvested with mechanical shakers, and it would be possible to modify those shakers to harvest jujubes. Depending on the cultivar, partial red jujube fruit could be stored for 1-2 months to extend the fruit marketing season (Kader et al., 1982; Yao et al., 2015b), whereas fruit with 1/3-1/2 red color is stored for 2-3 months in China (Chen et al., 2003; Fu, 2013).

Traditionally, over $90 \%$ of jujube fruit in China was consumed as sun-dried fruit (Guo and Shan, 2010). Now, fresh eating jujube consumption has greatly increased and the drying and processing methods have been diversifying in China (Liu and Wang, 2009; Liu et al., 2015). Compared with sun drying, heated drying (oven, heated room, or microwave drying) can reduce microbial contamination, ease management of drying parameters, increase product uniformity, and reduce drying time and labor costs (Guo and Shan, 2010). Heated drying also preserved more vitamin C, sugar, and other components (Wang et al., 2012; Zhang et al., 2004).

In addition to fresh eating and drying, jujubes also find many different culinary uses. Candied fruit used to be the dominant processed product in China, but now the processed jujube products have become more diversified. Jujubes can be processed into wine, juice, edible fiber, and even nucleotide drinks. Jujube honey is very popular in China and jujube wood can be used to make utensils and for carving (Guo and Shan, 2010; Liu and Wang, 2009).

With the exception of an ongoing research at the University of Idaho (E. Fallahi, personal communication), there is almost no other research on jujube processing in the United States. Possible jujube products include candied fruit, baked/smoked slices, jam, paste, ice cream, pie, and leather rolls. Most jujube products are rich in vitamin $\mathrm{C}$ compared with processed products from other fruits, making a good selling point for jujubes. Jujube also naturally has high sugar content (soluble solids content $25 \%$ to $35 \%$ ), and jujube snacks, such as dried, sliced, baked, and smoked fruit, do not need added sugar, which makes them healthier and in line with current health trends. 
Table 1. Jujube cultivar blooming types at Alcalde, NM (Yao et al., 2015a).

\begin{tabular}{lc}
\hline Blooming type & Cultivars \\
\hline Morning type & Abbeville, Chico, Don Polenski, Ed Hedgar, Fritzgerald, Fuping, GI-1183, \\
& Globe, Hupingzao, Jing-39, Jixin, Junzao, Lang, Mu, Mopanzao, Russia-2, \\
& Shuimen, So, Sugarcane, Sui, Thornless, Xiangzao, and Xingguang, \\
& Zaocuiwang \\
Ant Admiral, Banzao, Chaoyang, Dabailing, Daguazao, Dragon, GA-866, \\
Afternoon type & Honeyjar, Jin, Jinkuiwang, Jinsi-2, Jinsi-3, Jinsi-4, Kongfucui, Li, Li-2, \\
& Liuyuexian, Maya, Miyun, Pitless, Qiyuexian, Redland, September Late, \\
& Shanxi Li/Linyi Li, Sherwood, Sihong, Topeka, Tsao, Youzao, Yuanling, \\
& and Zhongning \\
\hline
\end{tabular}

Table 2. Jujube cultivar seed conditions of selected cultivars at Alcalde, NM (Yao et al., 2015a).

\begin{tabular}{ll}
\hline Seed condition & Cultivars \\
\hline Aborted seeds & Lang, Don Polenski, Junzao, and Xingguang \\
Low-filled seed percentage & Li, Li-2, Redland, Dabailing, and Daguazao \\
High-filled seed percentage & Zhongning, Abbeville, Jinsi-2, Globe, Chaoyang, \\
& September Late, Liuyuexian, Honeyjar, So, and Sugarcane \\
\hline
\end{tabular}

\section{JUJUBE PROPAGATION}

Jujubes can be propagated by root suckers, softwood cutting, grafting, or tissue culture. Grafting is still the dominant method used commercially (Liu et al., 2015). The rootstocks used for jujube grafting include jujube cultivar suckers, sour jujube seedlings, or a closely related species - China cointree, Paliurus hemsleyanus Rehder (mainly in southern humid areas of China) (Guo and Shan, 2010). In the United States, rootstocks are either jujube cultivar suckers or sour jujube seedlings. Sour jujube seeds are used because of their availability and stress tolerance. There were studies on jujube tissue culture propagation, but tissue culture was not widely adopted in China due to its cost and need for special facilities (Liu et al., 2015; Wang et al., 2002). When the United States demand for jujube plants is high enough, jujube tissue culture maybe possible, especially for major nurseries with well-established tissue culture techniques and facilities. Another option for orchard establishment is planting rootstock first and grafting in the field which reduces the cost for growers, as is done with walnut and other fruit species.

\section{NUTRITION AND ADAPTATION}

Jujube fruit is rich in vitamin $\mathrm{C}$, cyclic adenosine monophosphate (cAMP), cyclic guanosine monophosphate, polysaccharides, minerals, fiber, and antioxidants (Cyong and Hababusa, 1980; Cyong and Takahashi, 1982; Guo and Shan, 2010; Wang et al., 1956). Jujube fruit contains 200-600 mg/ $100 \mathrm{~g}$ fresh weight vitamin $\mathrm{C}$, which is 100 times higher than apples and 4-10 times higher than citrus (Bi et al., 1990; Liu, 2006; Yao, 2013, 2014). Jujube has been called the natural vitamin $C$ pill, and both jujube fruit and seeds have been widely used in traditional Chinese medicine. Over $60 \%$ of common traditional Chinese medicine prescriptions contained jujubes (Liu and Wang, 2009) to treat a wide range of illnesses including diabetes, diarrhea, skin infections, liver complaints, urinary disorders, obesity, fever, pharyngitis, bronchitis, anemia, insomnia, and cancer (Guo and Shan, 2010; Tahegorabi, et al., 2015). Jujube had the highest cAMP content among 180 plant species that were tested (Cyong and Hababusa, 1980; Liu and Wang, 1991). Li (2012) and Serezani et al. (2008) summarized the medicinal functions of cAMP. Jujube would be a convenient and natural source of cAMP (Li, 2012; Liu and Wang, 1991). Jujube cAMP syrup and jujube dietary fiber were available in the market in China (Liu et al., 2004, 2015). Recent studies indicated that some jujube components, especially triterpenic acids, had anti-inflammatory and antineoplastic effects (Choi et al., 2012; Gao et al., 2013; Huang et al., 2007; Plastina et al., 2012; Tahergorabi et al., 2015). These studies provided scientific support for the wide use of jujube fruit and seeds in traditional Chinese medicine.

Except for Heilongjiang Province and Tibet area, jujubes are widely grown in China between lat. $18^{\circ} 14^{\prime}$ to $45^{\circ}$ and long. $76^{\circ}$ to $124^{\circ}, 0$ to $2000 \mathrm{~m}$ elevation, and soil $\mathrm{pH} 5.5$ to 8.5 (Guo and Shan, 2010; Liu, 2006). Xinjiang region is becoming the number one jujube producing area in China both in acreage and yield, exceeding Heibei and Shandong provinces for the first time in history in 2014 (Liu et al., 2015). Xinjiang also produces the best dry jujube fruit in China commanding a premium price, two to five times higher than those fruit produced in Hebei and Shandong provinces. Jujube trees grow well in semiarid areas with hot summers, plenty of sunshine, and limited precipitation. Frequent precipitations near harvest can cause crop loss due to fruit splitting and mold/yeast infection. Jujubes also grow in a wide area in the United States and the best fruit is produced in the southwestern United States with similar climate conditions as Xinjiang area in China.

\section{CHALLENGES AND OPPORTUNITIES}

Limited commercially available cultivars, lack of cultivar trials, and limited research/ extension support greatly impede the expansion of jujube production in the United States.
Multistate cultivar trials are urgently needed for appropriate cultivar recommendations including identifying a few dominant widely adapted cultivars for mass production/processing while more diversified cultivars for local or specialized markets. In northern New Mexico with high elevation, late frosts, and a relatively short growing season, early season and midseason cultivars grow and produce well, but late cultivars do not. Fruit quality for fresh eating cultivars is excellent, but the fruit quality varies for drying cultivars. Winterhardiness is not a significant issue for jujubes since trees can tolerate temperatures as low as $-30{ }^{\circ} \mathrm{C}$ (Fairchild, 1918). Growing season temperatures and sunlight hours affect fruit quality, and some cultivars require higher temperatures for fruit setting. Studying cold storage parameters and exploring and developing convenient, processed jujube products are also critical for the industry's future. Jujube's high vitamin C and cAMP contents would be selling points for processed products.

Jujube hectarage is still limited in the United States, but interest in jujube is growing among both producers and consumers. With increased healthy food trends, consumers may value the nutritional content of jujubes. From the existing small-scale jujube orchards and backyard trees from El Paso, TX, Las Cruces to Espanola, NM, and from San Diego to Fresno, CA, jujube trees can produce reliable and abundant crops each year. In areas prone to late frost, like northern New Mexico, jujubes still produce a reliable crop. From 2010 to 2015, we harvested 1.5 apple crops in 6 years but six jujube crops at Alcalde, NM. On 15 May, 2014, the new growth of jujube trees was frost killed, but they regenerated, bloomed, set fruit, and matured (Yao and Zhao, 2016). Once established, jujube trees are drought tolerant, which is a critical characteristic for success in the drought-plagued southwestern United States, especially California. With the semiarid climate and abundant sunshine, jujube is an excellent fruit crop for the Southwest.

With more media coverage, promotional activities, and research/extension supports, more and more people could be exposed to jujubes. As jujube acreage grows, the high demands for plants would encourage leading nurseries to consider jujube tissue culture propagation. Without much insect/disease pressure, organic production of jujube would be less costly than organic apples or other pest-sensitive crops. For high-quality organic jujube fruit produced in southwestern United States, there is a domestic market as well as a potential export market to China.

\section{Literature Cited}

Ackerman, W.L. 1961. Flowering, pollination, selfsterility and seed development of Chinese jujube. Proc. Amer. Soc. Hort. Sci. 77:265-269.

Ashton, R. 2008. Jujube: A fruit well adapted to Texas. Texas Gardeners. 25 Nov. 2015. <http:// www.texasgardener.com/pastissues/janfeb08/ Jujube.html> . 
Bi, P., Z. Kang, F. Lai, and X. Lu. 1990. Fruit vitamin $\mathrm{C}$ content changes of different jujube cultivars (in Chinese). Shanxi Fruits 4:24-25.

Brubaker, M.M. 1977. The jujube in the Philadelphia area. The North American Pomona 10:82-83.

Chen, G., Z. Zhang, J. Ma, L. Zhao, and L. Cao. 2003. Studies on postharvest physiology and storage technology of Dongzao (in Chinese). Food and Machinery 2003(12):9-10.

Choi, S.H., J.B. Ahn, H.J. Kim, N.K. Im, N. Kozukue, C.E. Levin, and M. Friedman. 2012. Changes in free amino acid, protein, and flavonoid content in jujube (Ziziphus jujuba) fruit during eight stages of growth and antioxidative and cancer cell inhibitory effects by extracts. J. Agr. Food Chem. 60:1024510255.

Cyong, J. and K. Hanabusa. 1980. Cyclic adenosine monophosphate in fruits of Zizyphus jujuba. Phytochemistry 19:2747-2748.

Cyong, J. and M. Takahashi. 1982. Identification of guanosine $3^{\prime}: 5^{\prime}$-monophhosphate in the fruit of Zizyphus jujuba. Phytochemistry 21:1871-1874.

Fairchild, D. 1918. The grafted jujube of China. Heredity 9:2-7.

$\mathrm{Fu}, \mathrm{T} .2013$. Study on the technology of icetemperature storage of Dongzao jujube. $\mathrm{PhD}$ Diss. Tianjin University of Commerce, Tianjin, China (in Chinese).

Gao, Q.H., C.S. Wu, and M. Wang. 2013. The jujube (Ziziphus jujuba Mill.) fruit: A review of current knowledge of fruit composition and health benefits. J. Agr. Food Chem. 61:33513363.

Guo, Y. and G. Shan. 2010. The Chinese jujube. Shanghai Scientific and Technical Publishers, Shanghai, China (in Chinese).

Huang, X.D., A. Kojima-Yuasa, T. Norikura, D.O. Kennedy, T. Hasuma, and I. Matsui-Yuasa. 2007. Mechanism of the anti-cancer activity of Zizyphus jujube in HepG2 cells. Amer. J. Chinese Med. 35:517-532.

Kader, A.A., Y. Li, and A. Chordas. 1982. Postharvest respiration, ethylene production, and compositional changes in chinese jujube fruits. HortScience 17:678-679.

Li, L., J. Peng, and R. Bai. 2009. Analysis on the genetic relationships of Chinese Ziziphus with SRAP markers (in Chinese). Scientia Agricultura Sinica 42:1713-1719.

Li, Y. 2012. Research advances of cAMP in Ziziphus Jujube (in Chinese). Food Res. Dev. 33:230-231.

Liu, M. 2006. Chinese jujube: Botany and horticulture. Hort. Rev. 32:229-298.

Liu, M., J. Wang, P. Liu, J. Zhao, Z. Zhao, D. Li, X. Li, and Z. Liu. 2015. Historical achievements and frontier advances in the production and research of Chinese jujube (Ziziphus jujube) in China (in Chinese). Acta Horticulturae Sinica 42:1683-1698.

Liu, M. and M. Wang. 2009. Germplasm resources of Chinese jujube. China Forestry Publishing House, Beijing, China (in Chinese).

Liu, M., X. Wang, and T. Cui. 2004. Separating and extracting method for date cyclic nucleotide syrup, dietary fibre and date wax. Patent in China: CN02130757.1 (in Chinese).

Liu, M. and Y. Wang. 1991. CAMP content of Ziziphus jujuba Mill, Ziziphus spinosus $\mathrm{Hu}$ and other twelve horticultural plants (in Chinese). J. Hebei Agr. Univ. 14:20-23.

Locke, L.F. 1948. The chinese jujube: A promising fruit tree for the southwest, p. 78-81. In: Oklahoma Crops and Soils, 1947: Research reported at the Second Annual Oklahoma Crops and Soils Conference. Oklahoma Agr. Expt. Sta. Bul. B319.

Lyrene, P.M. 1979. The jujube tree. Fruit Var. J. 33:100-104.

Lyrene, P.M. 1983. Flowering and fruiting of chinese jujubes in Florida. HortScience 18:208-209.

Lyrene, P.M. and R.E. Crocker. 1994. The Chinese jujube. Univ. Florida Coop. Ext. Serv. Fact Sheet HS-50.

Meyer, F.N. 1911. Agricultural explorations in the fruit and nut orchards of China. USDA Bur. Plant Ind. Bul. 204. 25 Nov. 2015. <http://books.google. com/books? id=GqQUAAAAYAAJ\&printsec= frontcover\&source=gbs_ge_summary_r\&cad= $0 \# \mathrm{v}=$ onepage $\& \mathrm{q} \& \mathrm{f}=$ false $>$.

Meyer, F.N. 1916. China a fruitful field for plant exploration, p. 205-224. In: USDA yearbook of agriculture 1915. U.S. Dept. Agr., Washington, DC. 25 Nov. 2015. <http://naldc.nal.usda.gov/ download/IND43843025/PDF>.

Peng, J. H., Shu, Z. Sun, and S. Peng. 2000. Establishment of RAPD technical system and relationship of several cultivars in Chinese date (in Chinese). J. Agr. Biotechnol. 8(2):155-159.

Plastina, P., D. Bonofiglio, D. Vizza, A. Fazio, D. Rovito, C. Giordano, I. Barone, S. Catalano, and B. Gabriele. 2012. Identification of bioactive constituents of Ziziphus jujube fruit extracts exerting antiproliferative and apoptotic effects in human breast cancer cells. J. Ethnopharmacol. 140:325-332.

$\mathrm{Qu}$, Z. 1963. Cultivation of Chinese jujube in ancient China. J. Hebei Agr. Univ. 2(2):1-18. (in Chinese).

Qu, Z. and Y. Wang. 1993. Chinese fruit trees record-Chinese jujube. China Forestry Publishing House, Beijing, China (in Chinese).

Qu, Z., Y. Wang, J. Zhou, S. Peng, X. Qi, S. Cheng, and M. Liu. 1989. The observation of flowering characteristics of Chinese jujube (in Chinese). J. Hebei Agr. Univ. 12(1):1-9.

Rehder, A. and G.P. Rixford. 1929. Zizyphus, p. 3547-3548. In: L.H. Bailey (ed.). The standard cyclopedia of horticulture. MacMillan, New York, NY.

Serezani, C.H., M.N. Ballinger, D.M. Aronoff, and G. Peters-Golden. 2008. Cyclic AMP-Master regulator in innate immune cell function. Amer. J. Respir. Cell Mol. Biol. 39:127-132.

Tahergorabi, Z., M.R. Abedini, M. Mitra, M.H. Fard, and H. Beydokhti. 2015. "Ziziphus jujuba": A red fruit with promising anticancer activities. Pharmacogn. Rev. 9:99-106.

Thomas, C.C. 1927. Chinese jujube in southwestern United States, p. 212-215. In: USDA yearbook of agriculture 1926. U.S. Dept. Agr., Washington, DC. 25 Nov. 2015. <http:// naldc.nal.usda.gov/download/IND43842740/ $\mathrm{PDF}>$.

Wang, H., J. Chen, H. Fu, H. Zhang, S. Xiao, and B. Zhang. 2012. Change of several nutrients in jujube during drying process (in Chinese). Food Sci. 33(15):48-51.

Wang, H., Z. Chen, Z. Li, R. Wang, and Q. Zhou. 1956. The ascorbic acid content of jujube and its utilization by human subjects (in Chinese). Ying Yang Xue Bao 1:15-24.

Wang, J., M. Liu, and L. Dai. 2002. Advances in tissue culture of Chinese jujube (in Chinese). J. Fruit Sci. 19:336-339.

Yao, S. 2012. Jujube, chinese date in New Mexico. New Mexico State Univ. Coop. Ext. Publ. H330 .

Yao, S. 2013. Past, present and future of jujubesChinese dates in the United States. HortScience 48:672-680.

Yao, S. 2014. Vitamin C content of jujube fruit and its changes during fruit development and processing. HortScience 49(9S):S142 (abstr.).

Yao, S., J. Huang, and R. Heyduck. 2015a. Jujube (Ziziphus jujuba Mill.) flowering and fruiting in the Southwestern United States. HortScience 50:839-846.

Yao, S., R. Heyduck, and J. Huang. 2015b. Preliminary report on jujube cold storage and nutrient changes. HortScience 50(9S):S377S378. (abstr.).

Yao, S. and Z. Zhao. 2016. Jujube (Ziziphus jujuba) in the United States: Challenges and opportunities. Third international Jujube Symposium. Acta Hort. 1116:23-09.

Zhang, B., J. Chen, and Q. Li. 2004. Effects of drying methods on changes of $\mathrm{Vc}$, reducing sugar and total acidity in Chinese jujube (in Chinese). J. Northwest Sci-Tech Univ. of Agr. For. 32(11):117-121. 